\title{
Antibacterial and antioxidant activities of endophytic fungi extracts of medicinal plants from Central Sulawesi
}

\author{
Praptiwi, Marlin Raunsai, Dewi Wulansari, Ahmad Fathoni, Andria Agusta* \\ Natural Product Chemistry Laboratory, Reseach Center for Biology, Indonesian Institute of Sciences, Jl. Raya Bogor Km. 46, Cibinong 16911, Indonesia.
}

\section{ARTICLE INFO \\ Article history: \\ Received on: 09/12/2017 \\ Accepted on: 08/02/2018 \\ Available online: 31/08/2018}

\section{Key words:}

antibacterial, antioxidant, endophytic fungi,

bioautography.

\begin{abstract}
Endophytic fungi are a group of fungi which grow inside the plant tissues without causing negative symptoms to the host plant and are able to produce biologically active substances. This research was carried out to evaluate the antibacterial and antioxidant activity of 40 endophytic fungi isolated from 10 species of medicinal plants collected from Palolo, Central Sulawesi. Thin layer chromatography (TLC) bioautography guided screenings were done to evaluate antibacterial and antioxidant activities. The antibacterial activity was done against Staphylococcus aureus InaCC-B5 and Escherichia coli InaCC-B4, while antioxidant activity was assessed by 2,2-diphenyl-1-picrylhydrazyl (DPPH) method. Minimum inhibitory concentrations (MICs) of active extracts were further evaluated against these bacteria, while half-maximal inhibitory concentration $\left(\mathrm{IC}_{50}\right)$ of active extracts was determined by the microdilution broth method. The results of TLC bioautography screening showed 30 extracts inhibited the growth of $S$. aureus, 29 extracts inhibited the growth of E. coli, 27 extracts inhibited both $S$. aureus and E. coli, and 23 extracts posessed antioxidant activity. There were six extracts with MIC value of $<100 \mu \mathrm{g} / \mathrm{ml}$ against $S$. aureus and nine extracts with MIC value of $<100 \mu \mathrm{g} / \mathrm{ml}$ against $E$. coli. Six extracts indicated very strong antioxidant activity.
\end{abstract}

\section{INTRODUCTION}

Endophytic fungi are groups of fungi with very specific ecosystem inside plant tissues and produces varieties of secondary metabolites (Agusta, 2009). Secondary metabolites from endophytic fungi show important biological activities such as antioxidant, anticancer, immunomodulatory, antivirus, antituberculosis, anti-parasite and insecticides (Hussain et al., 2014). Endophytic fungi produce secondary metabolites similar to the host plant; therefore, endophytic fungi can be used as a source of producing active metabolites and leads in drug developments (Strobel, 2003; Owen and Hundley, 2004). The study on the isolation and evaluation of bioactivities of endophytic fungi from medicinal plants are increasing lately.

On the other hand, antimicrobial resistance has been a major concern in the health care system globally (Ferri et al., 2017). Discovery of novel and active metabolites against

${ }^{*}$ Corresponding Author

Andria Agusta; Natural Product Chemistry Laboratory, Reseach Center for Biology, Indonesian Institute of Sciences. Jl. Raya Bogor Km. 46, Cibinong 16911, Indonesia.E-mail: andr002@lipi.go.id pathogenic microbes as well as to overcome antimicrobial resistance become very important. In addition to health problems with increasing resistance, there is also a growing tendency to search natural antioxidants to overcome degenerative disease problems. Reactive oxygen species (ROS) are by-products of biological reactions that cause oxidative damage to biomolecules and play vital roles in programmed cell death (Cui et al., 2015). To overcome the negative effect of excessive ROS in human body, exogenous antioxidant is required. The main characteristic of antioxidant compounds is the ability to capture and stabilize free radicals (Prakash et al., 2011), inhibit or delay the occurrence of free radical reactions due to the presence of relative oxygen; these properties become important in the prevention of various diseases, such as cancer and coronary heart disease (Leong and Shui, 2002).

Medicinal plants are reported as host of some endophytic fungi that are involved in the co-production of active metabolites (Alvin et al., 2014). The study conducted by Ilyas (2009); Praptiwi et al. (2010); Praptiwi et al. (2015) showed that endophytic fungi isolated from medicinal plants such as gambier (Uncaria gambier), cinnamon (Cinnamomum burmannii) dan Zingiberaceous plants have antioxidant and/or antibacterial activity. 
Khiralla et al. (2015) has identified and classified 21 endophytic fungi from five medicinal plants of Sudan origin and some contain phenol compounds that have the potential as antioxidant natural sources. The present study aims to isolate and evaluate the antibacterial and antioxidant activity of endophytic fungi from ten species of medicinal plants originating from Palolo.

\section{MATERIAL AND METHODS}

\section{Material}

10 species of plants belonging to seven families which are Urticaceae (Villebrunea rebescens (Blume), Poikilospermum suaveolens (Blume) Merr.), Euphorbiaceae (Euphorbia heterophylla L., Acalypha caturus Blume), Asteraceae (Blumea balsamifera (L.) DC.), Zingiberaceae, Piperaceae (Piper peltatum L.), Lamiaceae (Plectranthus scutellarioides (L.) R. Br), and Verbenaceae (Cleodendron fragrans Wild.) were collected from Palolo, Central Sulawesi. Identification of the plant specimens were done at Herbarium Bogoriense, Research Center for BiologyIndonesian Institute of Sciences.

\section{Isolation of endophytic fungi}

Leaves, stems, and rhizomes collected from the field were stored at low temperature. After arriving in the laboratory, these samples were cleaned under tap water and immersed in $70 \%$ ethanol for 1 minutes, then immersed in 5.3\% Na-hypochlorite for 5 minutes and finally immersed in $70 \%$ ethanol for 30 seconds. Samples were dried under aseptic conditions. The sterilized samples were cut aseptically into small pieces $\left(1 \times 1 \mathrm{~cm}^{2}\right)$, and then, placed on top of the Corn Meal Malt Agar (CMMA) growth medium added with chloramphenicol $0.05 \mathrm{mg} / \mathrm{ml}$, and incubated at room temperature for 1 week. The emerging colonies were subcultured several times on Potato dextrose agar (PDA) to obtain pure isolates.

\section{Secondary metabolites extraction from endophytic fungi}

Pure isolate of endophytic fungi was cultured on broth medium [Potato dextrose broth (PDB)] $(200 \mathrm{ml})$ and incubated in dark condition, at room temperature for 3 weeks. After incubation period is completed, growth media and endophytic fungi biomass were extracted three times with ethyl acetate. The extract was evaporated by rotary evaporation and the concentrated extract was stored in the glass vial.

\section{Chemical compounds analysis by Thin Layer Chromatography (TLC)}

The analysis of chemical compounds of endophytic fungi extracts were performed on silica gel thin layer chromatography (TLC) plates (silica gel $\mathrm{GF}_{254}$, Merck). The dried extract was prepared in $10 \mathrm{mg} / \mathrm{ml} .10 \mu \mathrm{l}$ of extract was transferred on TLC plate and developed in $\mathrm{CH}_{2} \mathrm{Cl}_{2}: \mathrm{MeOH}$ (10:1). Separated chemical compounds were visualized under $254 \mathrm{~nm}$ and $366 \mathrm{~nm}$ ultraviolet (UV) light followed by spraying with spray reagent $1 \% \mathrm{Ce}\left(\mathrm{SO}_{4}\right)_{2}$ and $1 \%$ vanillin sulphuric acid.

\section{Detection of antibacterial activity by TLC-bioautography}

TLC-bioautography guided screening was performed to evaluate the antibacterial potency of endophytic fungal extracts.
$10 \mu 1$ of extract was transferred on TLC plate and dried. Plate was then dipped into bacterial suspension, followed by incubating the plate under humid condition for 18 hours at $37^{\circ} \mathrm{C}$. After incubation was completed, plates were sprayed with iodonitrotetrazolium p-violet (INT, Sigma). Growth inhibition of bacteria was observed by clear zone formation around the extract. The active extracts were further analyzed by developing the extract with mobile phase $\mathrm{CH}_{2} \mathrm{Cl}_{2}: \mathrm{MeOH}(10: 1)$. The plate was dried and sprayed with iodonitrotetrazolium p-violet (INT, Sigma).

\section{Detection of antioxidant activity by TLC-bioautography}

$10 \mu \mathrm{l}$ of extract was transferred on TLC plate and catechin used as positive control was also transferred on the TLC plate. The plate was dried and sprayed with $0.02 \% \mathrm{DPPH}$ in methanol. Yellow spot on purple background indicated the antioxidant activity. The active extract was developed with $\mathrm{CH}_{2} \mathrm{Cl}_{2}: \mathrm{MeOH}$ (10:1). After drying, plate was sprayed with $0.02 \%$ $\mathrm{DPPH}$ in $\mathrm{MeOH}$.

\section{Determination of minimum inhibitory concentration}

The minimum inhibitory concentration (MIC) of active extracts were determined by serial microdilution in 96-well microplate (Pessini et al., 2003). The wells in column A were filled with $100 \mu \mathrm{l}$ of Mueller-Hinton Broth (MHB) medium and $100 \mu \mathrm{l}$ stock solution of extract $(1024 \mu \mathrm{g} / \mathrm{ml})$ and homogenized. Columns B through $\mathrm{H}$ were filled with $100 \mu \mathrm{l}$ of MHB. A serial dilution was carried out with corresponding final concentration $(256 \mu \mathrm{g} / \mathrm{ml})$. The test was done in triplicate. After the dilution process, each well was added with $100 \mu$ of bacterial suspension $\left(10^{6} \mathrm{cfu} / \mathrm{ml}\right)$. In similar way, it was done with the positive control of chloramphenicol, growth media as negative control. Microtiter plate sealed with parafilm and incubated at $37^{\circ} \mathrm{C}$ for 24 hours. After incubation was completed, each well was added with 10 $\mu \mathrm{INT} 4 \mathrm{mg} / \mathrm{ml}$. The MIC was the lowest concentration showing clear wells that indicate the absence of bacterial growth.

\section{Determination of $\mathrm{IC}_{50}$ of active extract}

The $\mathrm{IC}_{50}$ of the extract was determined by serial microdilution in 96-well microplate by Takao et al. (2015) with minor modification. The wells in column A were filled with $195 \mu \mathrm{l}$ $\mathrm{MeOH}$ and $5 \mu \mathrm{l}$ extract $(10240 \mu \mathrm{g} / \mathrm{ml})$ and homogenized. Columns B through $\mathrm{H}$ were filled with $100 \mu \mathrm{l}$ of $\mathrm{MeOH}$. A serial dilution was carried out with corresponding concentration $(256 \mu \mathrm{g} / \mathrm{ml})$. After the dilution process completed, each well was added with $100 \mu \mathrm{l}$ of DPPH $(61.50 \mu \mathrm{g} / \mathrm{ml})$. Methanol was used as negative control, while catechin was used as positive control. Microplates were incubated in dark condition at room temperature for 90 minutes. The absorbances of the samples were measured at 517 $\mathrm{nm}$. Antioxidant activity index (AAI) was calculated as follows:

$\mathrm{AAI}=$ final concentration of $\mathrm{DPPH}$ in the reaction $/ \mathrm{IC}_{50}$ $\mathrm{IC}_{50}$ : the concentration of $50 \%$ inhibition was calculated by linear regression equation.

\section{RESULT AND DISCUSSION}

A total of 40 isolates of endophytic fungi recovered from 10 species of medicinal plants collected from Palolo, Central Sulawesi. The results in Table 1 show that a plant part is colonized 
by more than one endophytic fungus and different plant parts might have different composition of endophytic fungi community. This finding is in accordance with Zabalgogeazcoa (2008) that one species of plant inhabited by more than one endophytic fungus. Previous reports by Huang et al. (2008) and Ilyas (2009) showed similar results that one species of plant inhabited by various endophytic fungi. The distribution, composition, and population structure of endophytic fungi rely largely on the taxonomy, genetic background, age, and tissues of the host plants, and the types of environments (Sieber, 2007; Jia et al., 2016). Older plant parts may be colonized by higher number of endophytes than the younger ones (Zabalgogeazcoa, 2008).

Table 1: MIC of endophytic fungi extracts isolated from plants collected from Palolo, Central Sulawesi.

\begin{tabular}{|c|c|c|c|c|c|c|c|}
\hline \multirow{2}{*}{ No } & \multirow{2}{*}{ Sample } & \multicolumn{2}{|c|}{ MIC (ug/ml) } & \multirow{2}{*}{ No } & \multirow{2}{*}{ Sample } & \multicolumn{2}{|c|}{ MIC (ug/ml) } \\
\hline & & S. aureus & E. coli & & & S. aureus & E. coli \\
\hline 1 & PAL-01B1 & 64 & 64 & 21 & PAL-09D2 & NT & 256 \\
\hline 2 & PAL-01B2 & 32 & 32 & 22 & PAL-10B1 & 128 & 256 \\
\hline 3 & PAL-01D1 & NT & NT & 23 & PAL-10B2 & 256 & 128 \\
\hline 4 & PAL-01D2 & NT & 256 & 24 & PAL-10B3 & 128 & 8 \\
\hline 5 & PAL-02D1 & 128 & 256 & 25 & PAL-10D1 & 256 & 64 \\
\hline 6 & PAL-02D2 & 256 & NT & 26 & PAL-10D3 & 256 & 128 \\
\hline 7 & PAL-03B1 & 64 & 32 & 27 & PAL-10D8 & NT & NT \\
\hline 8 & PAL-03B2 & 256 & 128 & 28 & PAL-11B1 & NT & 256 \\
\hline 9 & PAL-03B3 & 128 & 256 & 29 & PAL-11B2 & NT & NT \\
\hline 10 & PAL-03D1 & 256 & 64 & 30 & PAL-11B3 & 128 & NT \\
\hline 11 & PAL-03D2 & 256 & 256 & 31 & PAL-11D1 & 64 & 256 \\
\hline 12 & PAL-04R1 & 256 & 256 & 32 & PAL-11D2 & 256 & 256 \\
\hline 13 & PAL-04R2 & 128 & 128 & 33 & PAL-14D1 & 64 & 128 \\
\hline 14 & PAL-07B1 & 8 & 8 & 34 & PAL-14D2 & 128 & 8 \\
\hline 15 & PAL-07B2 & 128 & 64 & 35 & PAL-14D3 & 256 & 64 \\
\hline 16 & PAL-07D1 & 256 & 128 & 36 & PAL-15B1 & 256 & 128 \\
\hline 17 & PAL-09B1 & 256 & NT & 37 & PAL-15B2 & NT & NT \\
\hline 18 & PAL-09B2 & 128 & 256 & 38 & PAL-15D1 & NT & 256 \\
\hline 19 & PAL-09B3 & NT & NT & 39 & PAL-15D2 & NT & NT \\
\hline 20 & PAL-09D1 & NT & NT & 40 & PAL-15D3 & NT & NT \\
\hline
\end{tabular}

\section{Analysis of the chemical compounds of the extract}

The chemical compounds of the endophytic fungi were analyzed by TLC in order to separate the chemical compounds within the extract. TLC is an important method for qualitative and quantitative analysis of drugs and has several advantages compared to HPLC and GC methods (Pyka, 2014). The plates were sprayed with color reagents (vanillin reagent and cerium reagent) to detect compounds in extract.

Observations under $254 \mathrm{~nm}$ showed different chemical compounds in each extract which emitted green and dark-colored compounds. A substance having a maximum wavelength $\left(\lambda_{\max }\right)$ of 250-260 nm may contain aromatic groups such as aromatic amino acid, simple phenol, and purines or pyrimidines (Harborne, 1973). Observation under $366 \mathrm{~nm}$ showed that TLC plates as background emitted purple and spot dark-colored chemical compounds. Substances having $\lambda_{\text {max }} 200-400 \mathrm{~nm}$ indicated the presence of compounds has an aromatic group or a conjugated double bond (Fried and Sherma, 1999). TLC plates sprayed with vanillin and cerium showed the presence of different chemical compounds in extract that was characterized by stain spots with multiple colors. Crude extract of endophyic fungi (Figure 1) contained several chemical compounds indicated by several spots with different $R_{\mathrm{f}}$. These chemical compounds might have biological activities and mixture of chemical compounds in crude extract may increase the potential of the active component to produce additive or synergistic effects, while others may be neutral or inhibit (Dhankhar et al., 2012).

\section{Antibacterial activity detection by TLC}

Antibacterial screening of endophytic fungi extracts was done by TLC method. TLC method is finest, rapid, efficient, and uncomplicated method (Masoko and Ellof, 2006; Shahverdi et al., 2007), requires small amount of test sample and simple interpretation of results (Valle Jr. et al., 2016). TLC dot-blot direct bioautography of antibacterial activity screening shown in Figure 2. The results of antibacterial screening of 40 endophytic fungi extracts showed that 30 extracts inhibited the growth of $S$. aureus, 29 extracts inhibited the growth of E. coli and 27 extracts were able to inhibit $S$. aureus as well as $E$. coli. The growth inhibition of bacteria was indicated by clear zone formation on TLC against a purple background (Das et al., 2010). The purple colour on TLC plate after spraying with INT was resulted from the conversion of INT to intensely colored formazan by the dehydrogenases enzyme of living microorganisms (Silva et al., 2005). Shahverdi et al. (2007) also stated that INT interacted with viable microorganisms caused a colour change of INT to red-purple one. Screening antibacterial activity by TLC dot-blot is simple and time saving method; however, the component mixtures in the crude extract 
can have synergistic or antagonistic effects (Choma and Jesionek, 2015). The active extracts developed with mobile phase to separate the bioactive compounds in the extract (Figure 3). Separated bioactive compounds with antibacterial properties indicated by white band formation.
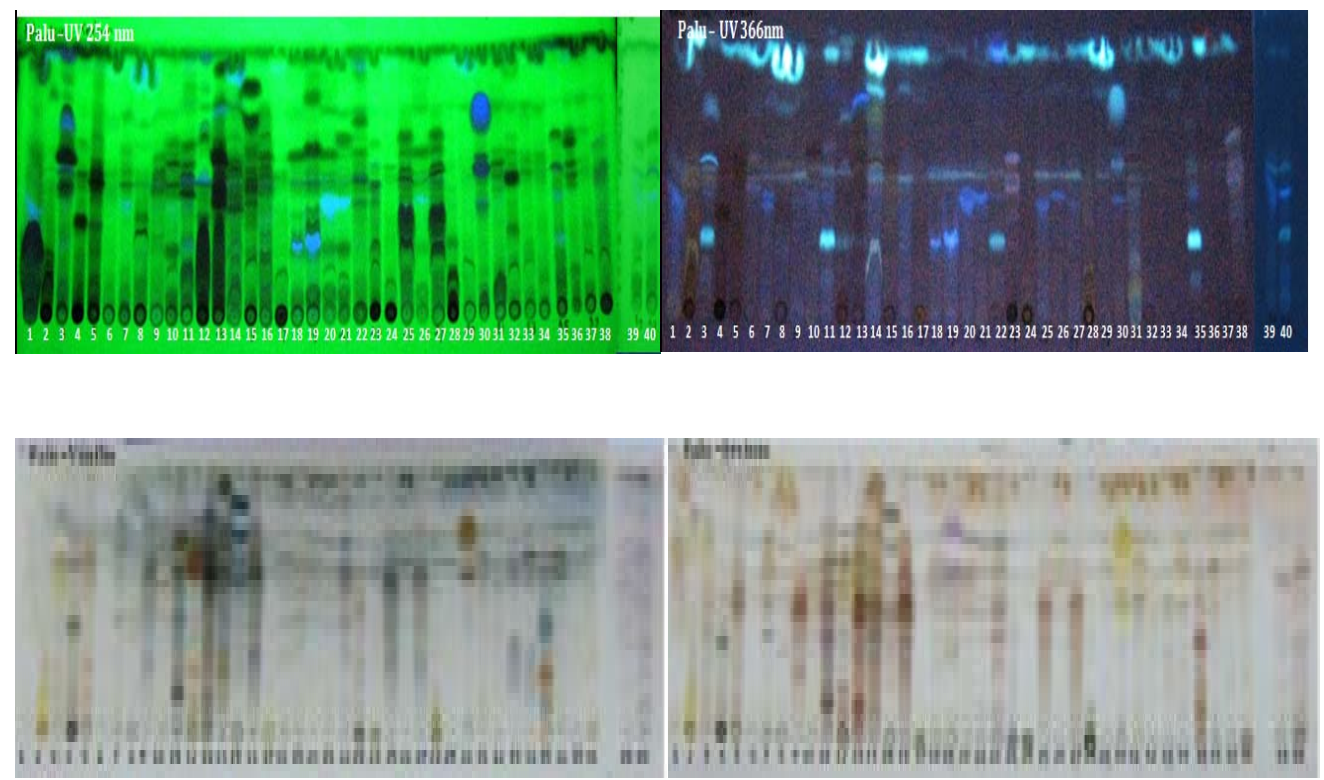

Fig. 1: Chromatograms of endophytic fungal extracts developed in dichloromethane-methanol (10:1 v/v), (a) viewed under $254 \mathrm{~nm}$ wavelength, (b) viewed under 366 $\mathrm{nm}$ wavelength, (c) sprayed with vanillin reagent, (d) sprayed with cerium reagent.

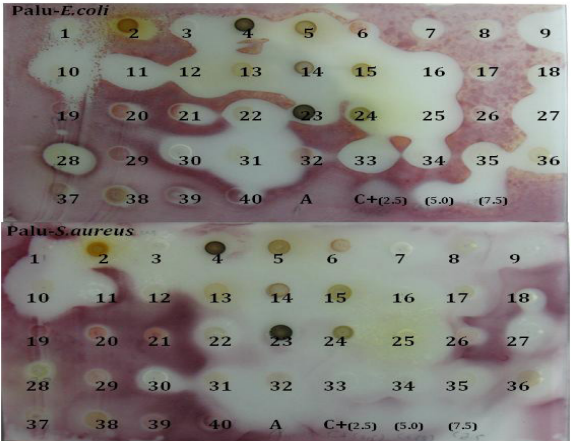

Fig. 2: TLC dot-blot assay for antibacterial activity of endophytic fungi against E. coli (top) and $S$. aureus (bottom).

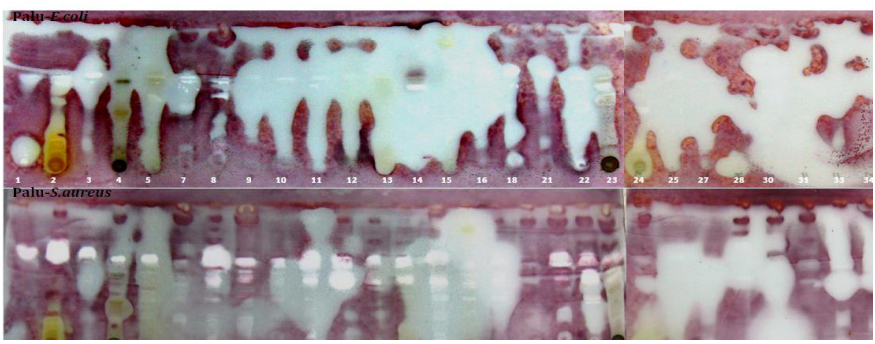

Fig. 3: Bioautograms of endophytic fungi against $E$. coli (top) and $S$. aureus (bottom). The TLC plates were developed in dichloromethane:methanol (10:1 $\mathrm{v} / \mathrm{v})$. Clear bands indicated antibacterial activity.

The minimum inhibitory concentration (MIC) of active extracts was assessed against $E$. coli and $S$. aureus. The result in Table 1 showed that MIC values of PAL endophytic fungi extracts ranging from 8 to $256 \mu \mathrm{g} / \mathrm{ml}$. MIC in the range of $100-1000 \mu \mathrm{g} /$ $\mathrm{ml}$ could be classified as antimicrobial (Borges et al., 2012). The MIC of several endophytic fungi were $<100 \mu \mathrm{g} / \mathrm{ml}$. According to Pessini et al. (2003), the MIC value of extract $<100 \mu \mathrm{g} / \mathrm{ml}$ was classsified as good antibacterial activity, while extracts with MIC value ranging from $100 \mu \mathrm{g} / \mathrm{ml}$ to $500 \mu \mathrm{g} / \mathrm{ml}$ classified as moderate activity. Among 40 endophytic fungi tested for antibacterial activity, endophytic fungus PAL-07B1 derived from Piper peltatum, has good antibacterial activity against $S$. aureus and $E$. coli, with equivalent MIC for both isolates $(8 \mu \mathrm{g} / \mathrm{ml})$. Several previous studies reported the antibacterial activity of ethyl acetate extracts of endophytic fungi isolated from Piper (Orlandelli et al., 2012; Astuti et al., 2014). This result suggested the endophytic fungus PAL-07-B1 contains potential bioactive compounds as antibacterial.

\section{Antioxidant activity by TLC-bioautography}

The antioxidant activity of extracts was done by DPPH free radical scavenging activity. DPPH radical when receiving an electron from antioxidant compound would be reduced to DPPH. The violet color of DPPH radical turned into yellow (Pavithra and Vadivukkarasi, 2015). Screening for antioxidant activity by dotblot TLC (Figure 4) showed 23 extracts had antioxidant activity. Antioxidant activity is indicated by the color change to yellow against a purple background (Dewanjee et al., 2015). The intensity of yellow color indicates the antioxidant capacity. Further analysis of active extract was shown in Figure 5.

The developed TLC-bioautography of endophytic fungi extracts (Figure 5) showed several compounds possess antioxidant activity within extract. This is indicated by the formation of 
yellowish white bands. Further analysis of active antioxidant extracts is to determine its $\mathrm{IC}_{50}$ value (Table 2).

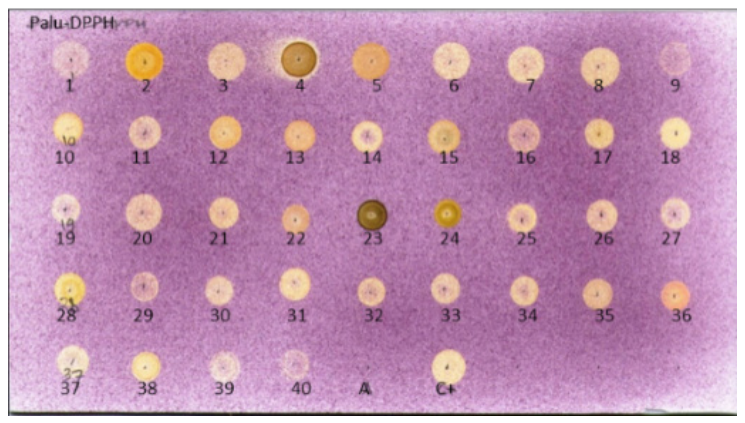

Fig. 4: TLC dot-blot assay for antioxidant activity of endophytic fungi extracts isolated from medicinal plants from Central Sulawesi.

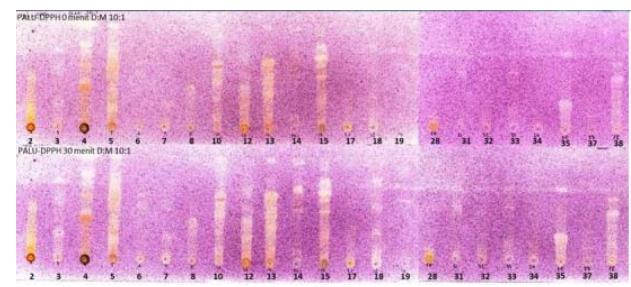

Fig. 5: TLC-bioautogram of antioxidant activity of endophytic fungi extracts. The yellowish white band indicates the compounds with antioxidant activity.

Table 2: $\mathrm{IC}_{50}$ and antioxidant activity index (AAI) of endophytic fungi extracts.

\begin{tabular}{ccccc}
\hline No & Sample & IC50 $(\mathbf{u g} / \mathbf{m l})$ & AAI value & Criteria of AAI value \\
\hline 1 & PAL-01B2 & 5.26 & 5.846 & Very strong \\
2 & PAL-01D2 & 7.84 & 3.922 & Very strong \\
3 & PAL-02D1 & 26.00 & 1.183 & Strong \\
4 & PAL-03D1 & 107.51 & 0.286 & Moderate \\
5 & PAL-04R1 & 52.70 & 0.583 & Moderate \\
6 & PAL-04R2 & 10.02 & 3.069 & Very strong \\
7 & PAL-07B2 & 77.60 & 0.396 & Moderate \\
8 & PAL-09B1 & 99.72 & 0.308 & Moderate \\
9 & PAL-11B1 & 10.03 & 3.066 & Very strong \\
10 & PAL-14D3 & 14.06 & 2.187 & Very strong \\
11 & PAL-15D1 & 43.15 & 0.713 & Moderate \\
12 & Catechin & 1.71 & 17.982 & Very strong \\
\hline
\end{tabular}

Based on the criteria of AAI value by Scherer and Godoy (2009), there are five extracts that displayed very strong antioxidant activity (PAL 01-B2, PAL 01-D2 from Villebrunearubescens (Urticaceae), PAL 04-R2 (Zingiberaceae), PAL 11-B1 from Clerodendronfragrans (Verbenaceae), and PAL 14-D3 from Acalyphacaturus (Euphorbiaceae); one extract displayed strong antioxidant activity and five extracts displayed moderate activity. Previous study by Praptiwi et al. (2016) showed some endophytic fungi isolated from Zingiberaceae had strong antioxidant activity, while endophytic fungi from other studied plants had no previous reports. The very strong antioxidant activity of extracts was related to many bioactive compounds as antioxidant within extract may act synergistically.

\section{CONCLUSION}

This study revealed the presence of bioactive secondary metabolites produced by endophytic fungi from several medicinal plants collected from Central Sulawesi with antibacterial and/or antioxidant activity. Endophytic fungi PAL-01B2 and PAL-07B1 showed good antibacterial activity against $S$. aureus InaCC-B5 and $E$. coli InaCC-B4. Five endophytic fungi showed very strong radical scavenging activity (PAL 01-B2, PAL 01-D2, PAL 04-R2, PAL 11-B1), and PAL 14-D3. Further studies needed to isolate and purify bioactive compounds, which is responsible for antibacterial and antioxidant activity. These findings indicated that endophytic fungi from medicinal plants collected from Palolo, Central Sulawesi could be potential for the development as pharmaceutical agents.

\section{ACKNOWLEDGEMENT}

The authors are thankful to Research Center for Biology, Indonesian Institute of Sciences for financial support through DIPA-Pusat PenelitianBiologi.

\section{REFERENCES}

Agusta A. 2009. Biologi dan Kimia Jamur Endofit. Bandung, Indonesia. InstitutTeknologi Bandung Publisher.

Alvin A, Miller KI, Neilan BA. Exploring the potential of endophytes from medicinal plants as sources of antimycobacterial compounds. Microbiol Res., 2014; 169(7-8):483-95. doi.org/10.1016/j. micres.2013.12.009.

Astuti P, Wahyono, Nababan OA. Antimicrobial and cytotoxic activities of endophytic fungi isolated from Piper crocatum Ruiz \& Pav. Asian Pacific Journal of Tropical Biomedicine, 2014, Volume 4, Supplement 2 Pages S592-S596.

Borges, A.; Saavedra, M.J.; Simões, M. The activity of ferulic and gallic acids in biofilm prevention and control of pathogenic bacteria. Biofouling, 2012, 28, 755-767.

Choma IM and Jesionek W. TLC-Direct Bioautography as a High Throughput Method for Detection of Antimicrobials in Plants. Chromatography, 2015, 2, 225-238; doi:10.3390/chromatography2020225.

Cui J-L, Guo T-T, Ren Z-X, Zhang N-S, Wang M-L. Diversity and antioxidant activity of culturable endophytic fungi from Alpine plants of Rhodolacrenulata, $R$. angusta and R. schalinensin. PLoS ONE, 2015; 10(3): e0118204. doi:10.1371/journal. pone.0118204.

Das K, Tiwari RKS, Shrivastava DK. Techniques for evaluation of medicinal plant products as antimicrobial agent: current methods and future trends.J. Med Plants Res, 2010; 4(2): 104-111. doi: 10.5897/ JMPR09.030.

Dhankhar S, Kumar S, Dhankhar S, Yadav JP. Antioxidant activity of fungal endophytes isolated from Salvadora oleoides Decne. Int J Pharm and Pharm Sci, 2012; 4 (2): 380-85.

Dewanjee S, Gangopadhyay M, Bhattacharyaa N, Khanra R, Dua TK. Bioautography and its scope in the field of natural product chemistry. Journal of Pharmaceutical Analysis, 2015; 5(2): 75-84.

Ferri M, Ranucci E, Romagnoli P, Giaccone V. Antimicrobial resistance: A global emerging threat to public health systems. Crit Rev Food Sci Nutr, 2017; 57(13):2857-2876. doi: 10.1080/10408398.2015.1077192.

Fried B, Sherma J. 1999. Thin-Layer Chromatography $4^{\text {th }} \mathrm{ed}$, revised and expanded. New York, USA. Marcel Dekker, Inc.

Harborne JB. 1973. Phytochemical methods A guide to modern techniques of plantanalysis $3^{\text {rd }}$ Ed. London Chapman \& Hall.

Huang W-Y, Cai Y-Z, Hyde KD, Corke H, Sun M. Biodiversity 
of endophytic fungi associated with 29 traditional chinese medicinal plants. Fungal Diversity, 2008; 33: 61-75.

Hussain H, Kliche-Spory C, Al-Harrasi A, Al-Rawahi A, Abbas G, Green IR, Schulz B, Krohn K, Shah A. Antimicrobial constituents from three endophytic fungi. Asian Pac J Trop Med, 2014; 7 (S1): S224-27. doi:10.1016/S1995-7645(14)60236-4.

Ilyas M. Biodiversity of endophytic fungi associated with Uncaria Gambier Roxb. (Rubiaceae) from West Sumatra. Biodiversitas, Journal of Biological Diversity, 2009; 10 (1): 23-28. doi:10.13057/biodiv/ d100105.

Jia M, Chen L, Xin H-L, Zheng C-J, Rahman K, Han T and Qin L-P. A Friendly Relationship between Endophytic Fungi and Medicinal Plants: A Systematic Review. Front. Microbiol., 2016; 7:906. doi: 10.3389/ fmicb.2016.00906.

Khiralla A, Mohamed I, Thomas J, Mignard B, Spina R, Yagi S, Laurain-Mattar D. 2015. A pilot study of antioxidant potential of endophytic fungi from some Sudanese medicinal plants. Asian Pac J Trop Med, 2015; 8 (9): 701-4. doi:10.1016/j.apjtm.2015.07.032.

Leong LP, Shui G. An investigation of antioxidant capacity of fruits in Singapore markets. Food Chemistry, 2002; 76 (1): 69-75. doi:10.1016/S0308-8146(01)00251-5.

Masoko P and Eloff JN: Bioautography indicates the multiplicity of antifungal compounds from twenty-four southern African Combretum species (Combretaceae). Afr J Biotechnol, 2006; 5:1625-1647.

Orlandelli, RC, Alberto RN, Almeida TT, Azevedo JL, Pamphile JA. In vitro Antibacterial Activity of Crude Extracts Produced by Endophytic Fungi Isolated from Piper hispidum. Journal of Applied Pharmaceutical Science, 2012; Vol. 2 (10), pp. 137-141. DOI: 10.7324/JAPS.2012.21027. ISSN 2231-3354.

Owen NL, Hundley N. Endophytes--the chemical synthesizers inside plants. Sci Prog., 2004; 87(Pt 2):79-99.

Pavithra K, Vadivukkarasi S. Evaluation of free radical scavenging activity of various extracts of leaves from Kedrostis foetidissima (Jacq.) Cogn. Food Science and HumanWellness, 2015; 4: 42-46.

Pessini GL, Dias-Filho BP, Nakamura CV, Cortez DAG. Antibacterial activity of extracts and neolignans of Piper regnellii (Miq.) C.DC. var pallescens (C.DC) Yunck. Mem. I. Oswalso Cruz 98, 1115-1120.

Prakash A, Rigelhof F, Miller E. Antioxidant activity. Eur Rev Med Pharmacol Sci, 2011;15 (4): 376-78. doi:10.1016/j.bmcl.2010.12.025.

Praptiwi, Jamal Y, Fathoni A, and Agusta A. Antimicrobial metabolite from the culture of endophytic fungus AFK-8 isolated from kayu kuning (Archangelisia flava (L.) Merr.) Proceeding of International Seminar: Biotechnology for Enhancement the Tropical Biodiversity, 2010; pp. 64-72.
Praptiwi, Ilyas M, Fathoni A, Wulansari D, and Agusta A. Antibacterial screening of the culture of endophytic fungal extracts isolated from cinnamon stick (Cinnamomum burmannii (Nees\&T.Nees) BLUME) Teknologi Indonesia, 2015; 38 (1): 33-41.

Pyka A. Review: Detection progress of selected progress in TLC. BioMed Research International, 2014; Volume 2014, Article ID 732078, http://dx.doi.org/10.1155/2014/732078.

Scherer R, Godoy HT. Antioxidant activity index (AAI) by the 2,2-diphenyl-1-picrylhydrazyl method. Food Chemistry, 2009; vol. 112 (3): 654-658.

Shahverdi AR, Abdolpour F, Monsef-Esfahani HR, Farsam H. A TLC bioautographic assayfor the detection of nitrofurantoin resistance reversal compound. J Chromatogr B AnalytTechnol Biomed Life Sci., 2007;850(1-2):528-30.

Sieber TN. Endophytic fungi in forest trees: are they mutualists? Fung. Biol. Rev., 2007:21:75-89.2007. doi:10.1016/j.fbr.2007.05.004. Accessed: January 4, 2018.

Silva MTG, Simas SM, Batista TGFM. Studies on antimicrobial activity, in vitro, of Physalis angulata L. (Solanaceae) fraction and physalin B bringing out the importance of assay determination. Mem. Instit. OswaldoCruz, 2005;100:779-782.

Strobel GA. Endophytes as sources of bioactive products. Microbes Infect., 2003; 5(6):535-44.

Takao LK., Imatomi M., and Gualtieri. Antioxidant activity and phenolic content of leaf infusions of Myrtaceae species from Cerrado (Brazilian savanna). Braz. J. Biol, 2014;75(4): 948-952.

Valle Jr. DL, Puzon JJM, Cabrera EC, andRivera WL. Thin Layer Chromatography-Bioautography and Gas Chromatography-Mass Spectrometry of Antimicrobial Leaf Extracts from Philippine Piper betle L. against Multidrug-Resistant Bacteria Evidence-Based Complementary and Alternative Medicine, 2016; Volume 2016, Article ID 4976791, http:// dx.doi.org/10.1155/2016/4976791.

Zabalgogeazcoa I. Review. Fungal endophytes and their interaction with plant pathogens. Spanish Journal of Agricultural Research, 2008; 6 (Special issue), 138-146. Available online at www.inia.es/sjar ISSN: 1695-971-X, Accessed: August 10, 2017.

How to cite this article:

Praptiwi, Raunsai M, Wulansari D, Fathoni A, Agusta A. Antibacterial and antioxidant activities of endophytic fungi extracts from medicinal plant from Central Sulawesi. J App Pharm Sci, 2018; 8(08): 069-074. 